\author{
Z. P. GAMA, P. MORLACCHI, A. GIORGI, G. C. LOZZIA, \\ J. BAUMG ÄRTNER
}

\title{
Towards a better understanding of the dynamics of Aphis spiraecola Patch (Homoptera: Aphididae) populations in commercial alpine yarrow fields
}

\begin{abstract}
The spatial distribution of Aphis spiraecola Patch was studied in two commercial yarrow fields located in the Swiss and Italian Alps and represented by Taylor's (1961) power law. The respective parameters indicate a highly aggregated distribution and lead to a high optimum sample size of 400-500 plants in the design of a sampling program. Opportunities for reducing the sampling efforts are discussed. The infestation patterns were studied on the basis of Vansickle's (1977) time varying distributed delay adequate for modelling the dynamics of age-structured populations. Published literature data were used to parametrize the functions representing the temperature-dependent duration and survival of the nymphal and adult stage. Likewise, literature data were available to obtain reliable estimates for the parameters of the fecundity function comprising the reproductive profile and the number of nymphs produced at different temperatures. The field data were used to parametrize the functions for wing formation and a compound mortality compromising the effects of plant senescence, stem cutting and natural enemies. The model satisfactorily represented the observed infestation patterns. However, there are opportunities for improving parameter estimation and validation. Moreover, the separation of the compound mortality into host plant and natural enemy effects would improve the mechanistic basis of the model and lead towards a tool that could be used to study bottom-up and top-down effects in the yarrow-aphid-natural enemy system.
\end{abstract}

Riassunto - Verso una migliore comprensione della dinamica di popolazioni di Aphis spiraecola Patch (Homoptera: Aphididae) in campi commerciali alpini di Achillea.

È stata studiata la distribuzione spaziale di Aphis spiraecola Patch in due campi coltivati di Achillea situati sulle Alpi italiane e svizzere; la distribuzione spaziale della specie è stata descritta dalla legge della potenza di Taylor (1961). I parametri specifici indicano una distribuzione spaziale fortemente aggregata e nel contesto di un programma di campionamento portano al calcolo di un'elevata dimensione ottimale del campione, pari a 400-500 piante. Le possibilità per una riduzione dell'impegno per il campionamento vengono discusse. 
Gli schemi di infestazione sono stati studiati sulla base del modello a ritardo distribuito a tempo variabile di Vansickle (1977), adatto per le dinamiche di popolazioni strutturate per età. I dati di letteratura sono stati usati per la parametrizzazione delle funzioni che descrivono la durata e la sopravvivenza temperatura-specifiche degli stadi di sviluppo preimmaginali e immaginali. Allo stesso modo, i dati di letteratura sono stati impiegati per ottenere stime affidabili per i parametri della funzione per la riproduzione, che comprende il profilo riproduttivo e il numero di neanidi prodotte a differenti temperature. I dati di campo sono stati utilizzati nella parametrizzazione delle funzioni formazione degli individui alati e mortalità complessiva, composta dai fattori senescenza della pianta, taglio del culmo e nemici naturali. Il modello descrive in modo soddisfacente gli schemi di infestazione osservati. Tuttavia esistono possibilità per il miglioramento della stima dei parametri e della validazione. Inoltre, la separazione della mortalità complessiva nelle componenti pianta ospite e nemici naturali migliorerebbe la base meccanicistica del modello e indirizzerebbe verso uno strumento che potrebbe essere usato nell' analisi degli effetti bottom-up e top-down nel sistema achillea-afidi-nemici naturali.

Key words: Aphis spiraecola, Achillea collina, spatial distribution, sampling plan, infestation pattern, delay model, parameter estimation, model validation

\section{INTRODUCTION}

Yarrow (Achillea collina Becker ex Rchb.) is cultivated for commercial purposes in the European Alps. Of interest in human medicine is the high content of secondary metabolites, i.e. organic compounds that are not directly involved in the normal growth, development, or reproduction of organisms (Fraenkel, 1959; Wink, 2003; Madeo et al., 2009). The aqueous and alcoholic extracts have digestive, antiphlogistic, spasmolytic, stomachic, carminative, and estrogenic properties (Benedek et al., 2007). In two fields located in the Southern Italian and Swiss Alps, Morlacchi et al. (2010) studied crop yield formation and recorded two insect communities of possible economic importance. The first community, not studied in this paper, consists of three leaf eating chrysomelids (Galeruca tanaceti L., Chrysolina marginata marginata L., Cassida spp.) and their natural enemies. The second community comprises three phloem feeding aphid species (Macrosiphoniella millefolli DeGeer, Aphis spiraecola Patch and Coloradoa achilleae Hille Ris Lambers), their parasites and the predator Coccinella septempunctata L. The populations of these aphids occurred in sufficiently high numbers as to possibly reduce the yield in terms of biomass on one hand and increase the contents of secondary metabolites on the other hand (Madeo et al., 2009). An adequate knowledge on the spatio-temporal dynamics of the aphid populations is indispensable for the design of an integrated pest and crop management system (Gutierrez and Baumgärtner, 2007).

The Spirea aphid A. spiraecola of interest in this paper is a polyphagous species of Far Eastern origin with a worldwide distribution (Wang and Tsai, 2000). It is a pest of citrus, apples and ornamentals, and transmits a number of plant viruses (Wang and 
Tsai, 2000). For supervised control purposes, Hermoso de Mendoza et al. (2006) defined intervention thresholds in Spanish citrus orchards. For rationalizing control, Hong et al. (2003) identified the sex pheromone and studied the circadian rhythm in release. The density-dependent effect of predators on A. spiraecola in apple orchards (Brown, 2004) stimulated attempts to manage $A$. spiraecola populations by enhancing biological control (Brown and Matthews, 2008). In a classical biological control effort, the aphelinid Aphelinus gossypii Timberlake was introduced into Florida to control A. spiraecola on citrus (Hoy and $\mathrm{Ru}, 2008$ ).

The purpose of this paper is to describe the spatial distributions, to design sampling plans, and to analyze, via the development of mechanistic population models, the temporal infestation patterns of. A. spiraecola in commercial alpine yarrow fields. The model parameters are estimated on the basis of published life table data (Wang and Tsai, 2000), the assumed formation of winged morphs (Holst and Ruggle, 1997) and the observed natural enemy presence (Morlacchi et al.,2010). The design of sampling plans and the analysis of infestation patterns should provide indications for obtaining reliable density estimates for model validation and population management purposes, and for improving the population model with respect to its mechanistic basis.

\section{MATERIAL AND METHODS}

\section{Study sites and population sampling}

For the study, we selected two commercial yarrow fields located in the Southern Alps (Poschiavo, Canton of the Grisons, Switzerland, $1140 \mathrm{~m}$ asl, and Dazio, Sondrio province, Italy, $900 \mathrm{~m}$ asl). At both locations, the farmers planted the variety 'Spak', selected by Valplantons BIO (Saillon, Switzerland) for a high content of secondary metabolites (Morlacchi et al., 2010). At the time of the study $(2007,2008)$, the plants were several years old and grown on black plastic mulch at a $0.5 \mathrm{~m} \times 0.5 \mathrm{~m}$ spacing. At Poschiavo, the plants were harvested on July 25 (2007) and July 30 (2008), while the Dazio grower renounced on cutting the plants during the year of observation (2008). This study deals with the dynamics of $A$. spiraecola populations inhabiting the two fields between the beginnings of April to the ends of July.

The fields at Poschiavo and Dazio were divided into 9 and 7 strata, respectively. In each of the strata, the beating tray method was applied to 3 randomly selected plants to obtain the number of A. spiraecola mummies of parasitized A. spiraecola, and coccinellid larvae and adults (Morlacchi et al., 2010). In the relatively small commercial yarrow fields, destructive sampling was not possible.

In 2007 and 2008, the Poschiavo field was visited 8 times (April 24, May 9, May 25, June 8, June 22, July 8, July 26, September 5) and twice (June 3, June 24), respectively. In 2008, the Dazio field was visited three times (June 3, June 24 and July 21). Since Morlacchi et al. (2010) did not find a significant difference between strata, the samples are treated as simple random samples taken from a homogenous sampling universe. 


\section{Spatial distributions and optimum sample size}

The sampling program provided the means, variances and standard errors of 13 samples. The ratio of the standard error to the mean is used to assess the reliability of the estimates.

The spatial distribution of A. spiraecola was described by Taylor's (1961) power law that expresses the variance $\left(s^{2}\right)$ in relation to the mean $(m)$ by

$$
s^{2}=a m^{2} .
$$

To obtain estimates for $a$ and $b$ through least square linear regression techniques, equation [1] was changed into $\ln (s 2)=\ln (a)+b \ln (m)$.

The optimum sample size is the smallest number $n$ of sample units that satisfies the objectives of the sampling program and achieves the desired precision of the estimate. For calculating $n$, we defined the reliability in terms of formal probabilistic statements with the length $D$ of the confidence interval equal to a proportion of the mean (Karandinos, 1976). The consideration of equation [1] yields the optimum sample size $n$

$$
n=\left(\frac{z_{\alpha / 2}}{D}\right)^{2} a m^{b-2}
$$

where $z_{\alpha / 2}$ is the upper $\alpha / 2$ point of the standard normal distribution. The definition of the optimum sample size $n$ depends on the objective of the sampling program (Karandinos, 1974). The values of $\mathrm{z}_{\alpha / 2}=1.65$ and $D=0.3$ reflect a high end of a range that is considered reasonable for pest management purposes (Hutchison et al., 1988).

\section{Basic model}

If the variability in developmental time is high relative the mean developmental time, a stochastic model may be appropriate (Di Cola et al., 1999). In this work, we use the time varying distributed delay of Vansickle (1977) to model the development of both the nymphal and adult cohorts. However, we limit the description of the model to the basic elements only and refer the reader to the recent examples of Gutierrez (1996), Holst and Ruggle (1997), Alilla et al., 2005, Severini et al. (2009), Gutierrez and Baumgärtner (2007) and Limonta et al. (2009a;b) for additional explanations and applications. Briefly,

$$
\frac{d r_{i}(t)}{d t}=\frac{k}{D E L(t)}\left[r_{i=1}(t)-r_{i}(t)\left(1+A R(t) \frac{D E L(t)}{k}+\frac{d D E L(t)}{d t}\right)\right]
$$

where $t=$ time [days], $r_{i}(t)=$ the transition rate of the $i$-th sub-stage, $k=$ number of delay sub-stages, $D E L(t)=$ time dependent developmental time [days] in absence of losses, and $A R(t)=$ time dependent proportional losses or attrition. The output $r_{k}(t)$ of the nymphal 
stage becomes the input $x(t)$ into the adult stage. For constant temperatures and a cohort input $x(t)$ into the first sub-stage, Vansickle (1997) describes the procedures for obtaining estimates for the parameters $k, D E L(k)$ and $A R(t)$ as follows.

$$
\begin{aligned}
& k=\frac{\mu^{2}}{s^{2}} \\
& D E L=\mu \varepsilon \\
& A R=k\left[\frac{1}{\mu}-\frac{1}{D E L}\right]
\end{aligned}
$$

where $\mu$ is the observed developmental time with $s^{2}=$ variance, and $\varepsilon=$ stage-specific survival. The input into the larval stage corresponds to the below described fecundity rate, while input into the adult stage corresponds to the output of the larval stage modified by the proportion of emigrating winged aphids. The survival of larvae depends on temperature and the compound effect of predation, parasitism, plant senescence and cutting. These model components are described in the next section. For simulation purposes, we select a time increment of $1 \mathrm{~h}$ for which the mean temperature is calculated on the basis of a cosine function fitted through the daily temperature maxima and minima (Bianchi et al., 1990).

\section{Model components}

The developmental rate of nymphs and adults is represented by the model of Brière et al. (1999)

$$
\mu(T)=\alpha T\left(T_{l}-T\right)\left(T_{u}-T\right)^{\beta}
$$

where the $T_{l}$ and $T_{u}=$ the lower and upper thresholds for development, $\alpha$ and $\beta=$ parameters. While $T_{u}$ has been estimated from experiments and $\beta$ has been set to 0.5 (see Brière et al. 1999), $T_{l}$ and $\alpha$ have been estimated via linear least square regression techniques applied to the data of Wang and Tsai (2000). The intrinsic survival $e$ of larvae only is represented on the basis of a Beta function

$$
\varepsilon(T)=\lambda\left(T-T_{l}\right)^{\xi}\left(T_{u}-T\right)^{5}
$$

whose parameters $\lambda, \xi$, and $\varsigma$ were estimated by applying linear least square regression techniques to the data reported by Wang and Tsai (2000). The values are reported in Tab. 1. Following Curry and Feldman (1987), the reproduction is based on the reproductive profile $f_{i}$ i.e. the normalized age-specific fecundity rate in the $i$-th sub-stage, and the temperature-dependent total fecundity $F(T)$ 


$$
\begin{aligned}
& f_{i}=\frac{\tau i}{v^{i}} \frac{1}{R} \\
& F(T)=\phi\left(T-T_{i}\right)^{y}\left(T_{a}-T\right)^{\prime}
\end{aligned}
$$

The parameters $\tau, v \phi \phi$ and $\iota$ are estimated by applying linear least square regression techniques to the data reported by Wang and Tsai (2000), while $R$ corresponds to the total per capita fecundity realized over the $k$ sub-stages. The product of eqs. 6 and 7 multiplied by the $i$-th transition rate of equation $3 \mathrm{a}$ and the time step length $(1 / 24)$ yields the fecundity of the $i$-th age group per time step with temperature $T$. The reproduction of the adults, becoming the input $x(t)$ into sub-stage 1 of equation 3a, in all age groups, is obtained by summing the fecundities realized in all sub-stages $(i=1,2, . . k)$. Curry and Feldman (1987) provide further details on modelling reproduction under time-varying temperature conditions.

The proportion $w(N)$ of winged aphid depending on aphid density $(N)$ is derived from Holst and Ruggle (1997)

$$
w(N)=\frac{1}{1+e^{-v \ln (N)+\omega}}
$$

According to the field observations reported in Fig. 1, the proportion $w(N)$ may be low (0.05) and high (0.99) at densities $N=20$ and $N=40$, respectively. This tentative interpretation allows the calculation of the parameters $v$ and $\omega$ reported in Tab. 2. As indicated above, the input $x(t)$ into the adult stage is modified by $(l-w(N))$.

The physiological time-dependent compound effect $v(\tau)$ of natural enemies, plant senescence and cutting is represented by

$$
v(\tau)=\frac{1}{1+e^{-\rho \ln (\tau)+\psi}}
$$

where $\tau=$ physiological time in day-degrees (dd) above the lower developmental threshold $T_{u}$. The field observations reported in Fig. 1 suggest a small value for $v(\tau)=$ 0.05 at $\tau=1200 \mathrm{dd}$ and high value $v(\tau)=0.99$ at $\tau=1600 \mathrm{dd}$. This tentative interpretation allows the calculation of the parameters $\rho$ and $\psi$ reported in Tab.1. The product of the stage specific survival of nymphs (equation 5$)$ and $(1-v(\tau))$ for both nymphs and adults is the basis for the calculation of attrition $A R(t)$ according to equation $3 \mathrm{~d}$.

\section{Model validation}

The validation procedures consist of testing the model capabilities with respect to its intended use (Rykiel, 1996) which is the mechanistic representation of infestation patterns. The predictions of the model are compared to the observations made in 2007 
and 2008 in the Poschiavo yarrow field. This field may receive higher radiation levels and is located at a lower altitude than Robbi-Poschiavo where the temperature was recorded. Moreover, the field is situated near a lake with presumably mitigating effects on low temperatures. To take into account these observations, the daily temperature maxima and minima recorded at Robbi-Poschiavo were increased by $1.0^{\circ} \mathrm{C}$, and the resulting values were used to calculate the hourly mean temperatures. Taking into account the observed infestations, the simulation tentatively starts with a density of 5 medium age nymphs in sub-stage $i=35$ on day 100 corresponding to 391 daydegrees after January $1^{\text {st }}$.

The infestation patterns was simulated first with intrinsic parameters only, i.e. in absence of the effect of wing formation and compound mortalities. Second, the infestation pattern was simulated with intrinsic parameters and wing formation but absence of compound mortality effects. Third, the infestation patterns were simulated with intrinsic parameters, wing formation and compound mortality.

\section{RESULTS}

Fig. 1 shows the logarithm of the variance plotted against the logarithm of the mean density for each sample. The parameters $a=\exp (2.6552)$ and $b=1.926$ reported in Tab. 1 indicate, for the sampling method used here, a highly aggregated distribution of A. spiraecola.

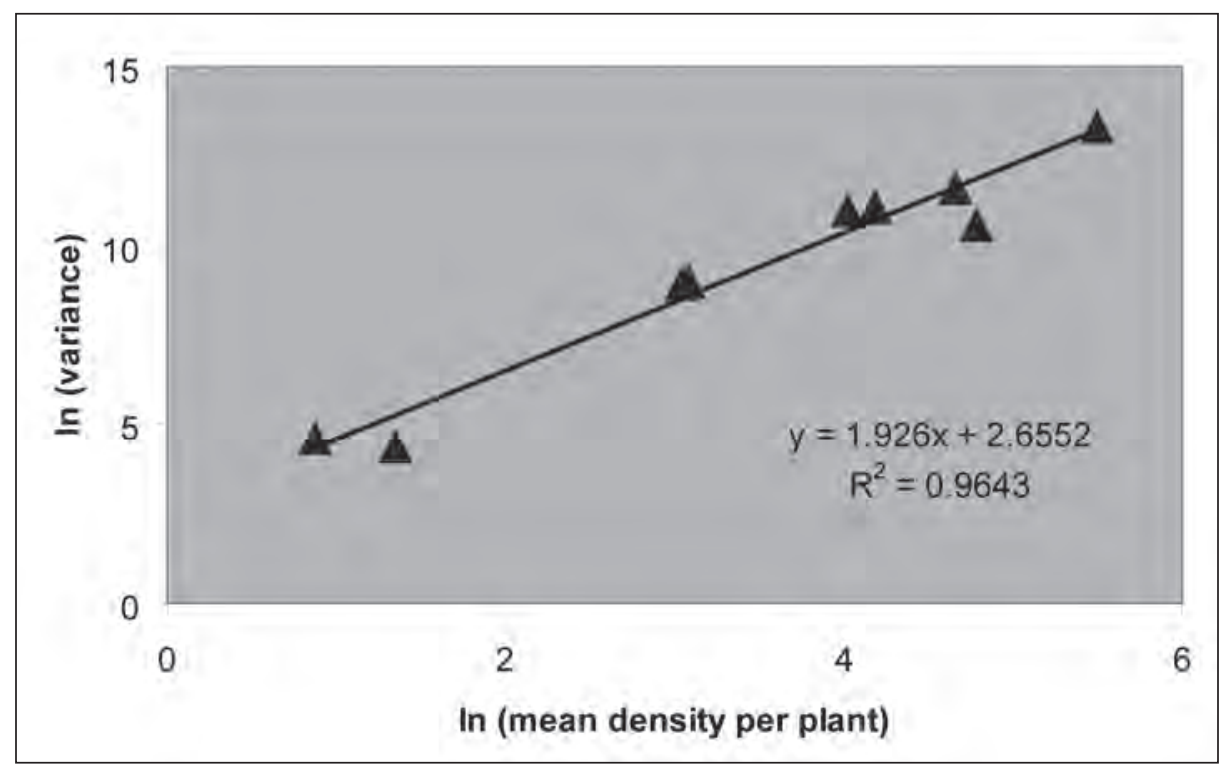

Fig. 1. The relationship between $\ln$ (variance) and $\ln$ (mean) density of Aphis spiraecola sampled in two alpine yarrow fields. 
Fig. 2 shows the optimum sample size, i.e the number of pants to be sampled for estimating the densities with $z_{\alpha / 2}=1.65$ and $D=0.3$. Accordingly, to obtain reliable density estimates for research purposes at low densities, the high number of about 500 plants needs to be sampled. This requires high investments into sampling studies and relatively big fields to facilitate random sampling. A high proportion of samples may require finite population corrections in statistical analyses (Cochran, 1977). To obtain reliable estimates for population management purposes, the optimum sample size can be reduced to the still high number of 400 plants.



Fig. 2. The optimum number of plants required for estimating the density of Aphis spiraecola with a predefined level of reliability (the standard normal variate $\mathrm{z}_{\alpha} / 2=1.65$, and the ratio of the standard error to the mean $\mathrm{D}=0.3$ ).

Tab. 1 lists the parameter estimates for Taylor's (1961) spatial distribution model $(a, b$, equation 1), for the order of the Vansickle's (1977) delay ( $k$, equation 3$)$, for the developmental rate according to Brière et al. (1999) $\left(\alpha, \beta, T_{l}, T_{u}\right.$, equation 4), and for the stage-specific intrinsic survival $(\lambda, \xi, \varsigma$, equation 5$)$. While the spatial distribution is described for the combined densities of adults and nymphs, the two life stages are separated in the study on aphid infestations. Consequently, the order of the delay and the developmental rate parameters differ between nymphs and adults. Only nymphs suffer from intrinsic mortalities, while adult survivorship is controlled by the order of the delay. The order $k=13$ satisfactorily yields the observed adult survivorship in the data of Wang and Tsai (2000). Noteworthy is the relatively low developmental threshold obtained for both life stages. 
Table 1. Estimates for the parameters of Taylor's (1961) spatial distribution model (a,b, equation 1 ), for the order of the delay ( $k$, equation 3$)$, for the developmental rate ( $\alpha, \beta, T_{l}, T_{w}$, equation 4$)$, and for the stage-specific intrinsic survival $(\lambda, \xi$,, , equation 5) of Aphis spiraecola.

\begin{tabular}{|c|c|c|c|c|c|c|c|c|c|c|}
\hline $\begin{array}{c}\text { Life } \\
\text { stages }\end{array}$ & \multicolumn{2}{|c|}{$\begin{array}{c}\text { Spatial } \\
\text { distribution }\end{array}$} & $\begin{array}{c}\text { Delay } \\
\text { order }\end{array}$ & \multicolumn{4}{|c|}{ Developmental rates } & \multicolumn{3}{c|}{ Intrinsic survival } \\
\hline & $\mathrm{a}$ & $\mathrm{b}$ & $\mathrm{k}$ & $\alpha$ & $\beta$ & $\mathrm{T}_{1}$ & $\mathrm{~T}_{\mathrm{u}}$ & $\lambda$ & $\xi$ & $\varsigma$ \\
\hline nymphs & 14.228 & 1.926 & 71 & $7.97 \mathrm{E}-05$ & 0.5 & 2.3 & 35.0 & 0.015 & 0.782 & 0.792 \\
\hline adults & & & 13 & $5.09 \mathrm{E}-04$ & 0.5 & 2.3 & 35.0 & & & \\
\hline
\end{tabular}

Tab. 2 lists the parameter estimates for the reproductive profile, the fecundity, the wing formation and the compound mortality function. The data provided by Wang and Tsai (2000) were sufficient to obtain satisfactory estimates for the former two functions, while Holst and Ruggle (1997) provided only the basic model for density-dependent wing formation. The parameters of this function as well as the parameters of the compound mortality function were obtained by comparing model predictions with observed infestation patterns. Noteworthy, the compound effect depends on physiological time rather than density. Hence, the model disregards possible density-dependent effects of natural enemies and the host plant on A. spiraecola populations.

Tab. 2. Parameter estimates for the reproductive profile ( $\tau$, $v, R$, equation 6$)$, for the temperaturedependent fecundity ( $\phi, \phi, \iota$, equation 7$)$, for the density dependent wing formation ( $v, \omega$, equation $8)$, and for the physiological time-dependent stage-specific compound mortality of Aphis spiraecola ( $\varrho, \psi$, equation 9).

\begin{tabular}{|c|c|c|c|c|c|c|c|c|c|c|}
\hline $\begin{array}{c}\text { Life } \\
\text { stages }\end{array}$ & \multicolumn{2}{|c|}{$\begin{array}{c}\text { Reproductive } \\
\text { profile }\end{array}$} & \multicolumn{3}{c|}{ Fecundity } & \multicolumn{2}{c|}{$\begin{array}{c}\text { Wing } \\
\text { formation }\end{array}$} & \multicolumn{2}{c|}{$\begin{array}{c}\text { Compound } \\
\text { mortality }\end{array}$} \\
\hline & $\tau$ & $v$ & $\mathrm{R}$ & $\varnothing$ & $\phi$ & $\mathrm{\iota}$ & $v$ & $\omega$ & $\rho$ & $\psi$ \\
\hline nymphs & & & & & & & & & 15.8274 & 112.2685 \\
\hline adults & 7.97 & 1.27 & 42.37 & 0.000556 & 2.335 & 1.694 & 6.3677 & 26.4214 & 15.8274 & 112.2685 \\
\hline
\end{tabular}

The infestation patterns of A. spiraecola in the Poschiavo yarrow field is depicted in Fig. 3. Accordingly, A. spiraecola increases after the beginning of April until July and decreases thereafter to low numbers. Morlacchi et al. (2010) observed a second peak in September which is not considered in this work. In all samples, the ratio of the standard error to the mean high was (from 0.31 to 0.94 ) indicating a low level of reliability of the density estimates. Nevertheless, the low reliability is considered as sufficient for validating the predicted infestation patterns.

As expected, the disregard of wing formation and compound mortality predicts an ever increasing population during the time under study (Fig. 3). The slow increase is due to the relatively low temperatures of the alpine environment. The density-dependent wing formation stabilizes the population in summer. As previously mentioned, the population suffers in summer from losses due to natural enemies, plant senescence and cutting 
(Morlacchi et al., 2010). Only the consideration of the physiological-time dependent compound mortality reduces the population to low levels in mid summer (Fig. 3).

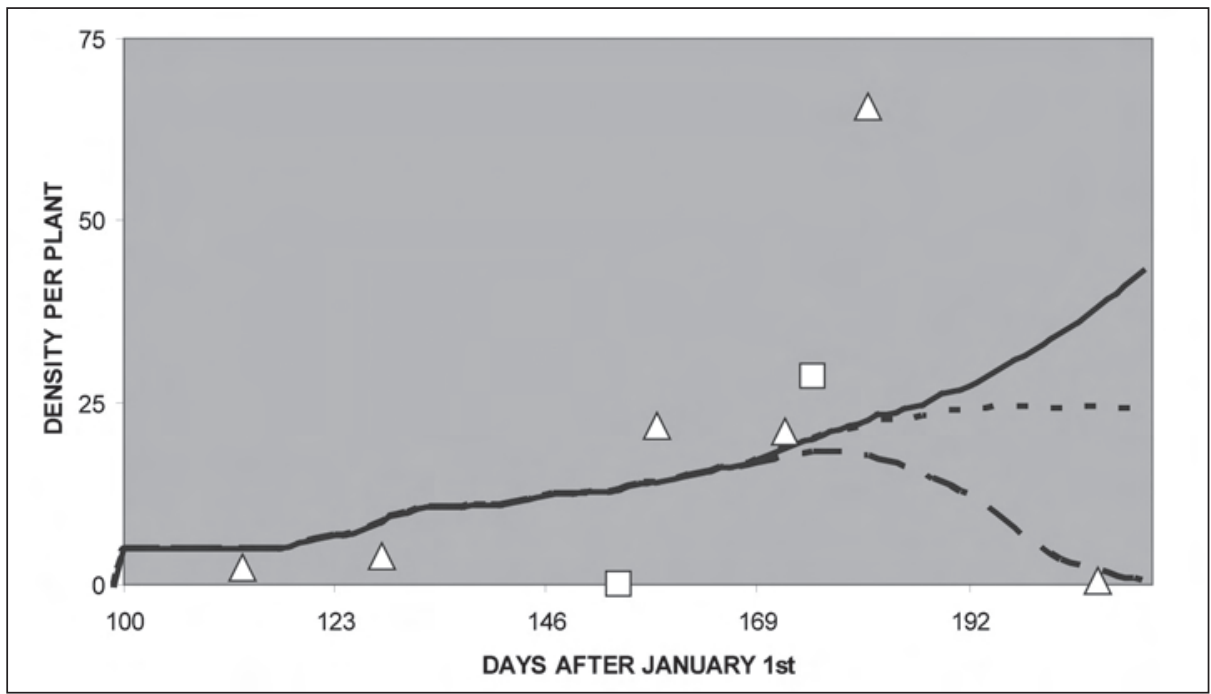

Fig. 3. Simulated and observed infestation patterns of Aphis spiraecola in the Poschiavo yarrow field (triangles for 2007 data, quadrats for 2008 data). The line indicates the simulated patterns in absence of wing formation and compound mortalities, the dots indicate the simulated patterns without compound effect of mortalities, the dashed line indicates the simulated pattern with wing formation and compound mortalities (the density of 119.81 aphids on May 10, 2007, is omitted).

\section{DISCUSSION}

The parameters of Taylor's power law represented in equation 1 indicate a highly aggregated distribution among plants. The relatively big physical size of the sampling unit (plant) may have contributed to the relatively high sampling factor of $a=14.2278$. Possibly, the selection of a whole plant sample unit rather than the consideration of plant parts is responsible for this result (Morlacchi et al., 2010).

According to the enumerative sampling plan, the optimum sample size consists of $400-500$ plans. This indicates that the sample size of 27 plants used in this work, albeit satisfactory for monitoring infestation patterns, is too low for estimating population densities in analyses of the population dynamics. The optimum sample size, resulting from the high values of the parameters of Taylor's law (1961), requires considerable investments in sampling activities. However, there are possibilities for reducing the efforts even if non-destructive sampling is required. Apart from a revision of the reliability levels, there are three opportunities for making sampling more efficient. First, it may be possible to rely on visual examinations rather than on the beating tray technique. Second, during the reproductive growth phase, the design of a two-stage sampling plan with plants as 
primary and stems as secondary sampling units may be feasible (e.g. Cochran, 1977). Third, the substitution of enumerative by binomial sampling plans may also reduce the investments into sampling activities (Morlacchi et al., 2010).

In absence of wing formation and compound effects of the host plant, cutting and natural enemy activity, the model predicts slowly increasing aphid densities (Fig. 3). The slow increase may be due to the low temperatures in the alpine environment. At the beginning of the infestation, higher temperatures as expected in apple and citrus growing areas would produce a higher increase. The model parameters have been estimated from life table data obtained on citrus with a Florida aphid biotype (Wang and Tsai, 2000). In a subsequent paper, Tsai and Wang (2001) demonstrated how different host plants affect the life table statistics of A. spiraecola. To put parameter estimates on a more solid ground than done in this paper, we recommend the construction of life tables for the alpine biotype of A. spiraecola on the Spak yarrow cultivar.

In absence of wing formation and compound effects of the host plant, cutting and natural enemy activity, the model was parametrized with the data of Wang and Tsai (2000) and visually compared with an independent data set. The consideration of wing formation and compound mortality effects, however, was only possible by using the same field data for both parameter estimation and model testing. To overcome this limitation, more field data, preferably taken in different environments, should be collected and used for model validation against independent data sets. Additional field and laboratory data are also required for creating a more solid ground for the formulation of wing formation and for extending the model towards the development of other morphs than winged and wingless individuals, and towards the development of overwintering eggs. This would allow a more satisfactory initialization of the model than done here.

The compound mortality consists of the combined effect of natural enemies, plant senescence and cutting (Morlacchi et al., 2010). The separation of the compound effect into different components would undoubtedly improve the mechanistic basis of the model. A comparison between the Poschiavo field, where the plants have been harvested, and the Dazio field, where the grower renounced on harvesting in the year under study, indicates that cutting strongly affects the aphid dynamics. Additional field studies on the effects of cutting on aphid survival and the on-going studies on the interactions between aphids and the yarrow host plant (Madeo et al., 2009), on one hand, hold the promise for separating plant effects from predation in further model development. The on-going studies on the interactions between aphids and natural enemies (Morlacchi et al., 2010), on the other hand, could lead to a separation of biological control from plant effects. Brown and Matthews (2008) remind us that natural enemy activity is important in some but not all studies on aphid population dynamics. Finally, the resulting model could be used to study bottom-up and top-down effects in the yarrow-aphid-natural enemy system. In a recent publication, Miller (2008) may have proposed an adequate hypothesis by stating that it is now widely accepted that herbivore dynamics can be influenced by both bottom-up and top-down forces, and their relative importance can vary spatially and temporally. 


\section{ACKNOWLEDGEMENTS}

The daily maximum and minimum temperatures of Robbi-Poschiavo were kindly made available by MeteoSchweiz, 8044 Zürich.

\section{REFERENCES}

Alilla R., Severini M., Pesolillo S., 2005 - Modello a ritardo distribuito a temperatura variabile per la simulazione dello sviluppo ontogenetico in stadi giovanili di popolazioni peciloterme. Rivista Italiana di Agrometeorologia, 3: 30-33.

Benderoth M., Textor S., Windsor A.J., Mitchell-Olds T., Gershenzo J., Kroyman J., 2006 - Positive selection driving diversification in plant secondary metabolism. Proc. Natl. Acad. Sci. USA,. 103 (24): 9118-9123.

Benedek B., Gjoncaj N., SAuKel J., Kopp B., 2007 - Distribution of phenolic compounds in Middleeuropean Taxa of the Achillea millefolium L. Aggregate. Chem. Biodivers., 4:849-857.

Bianchi G., BAumgäRtner J., Delucchi V., Rahalivavololona N., 1990 - Modèle de population pour la dynamique de Maliarpha separatella Ragonot (Pyralidae, Phycitinae) dans les rizières du lac Alaotra. J. Appl. Ent., 110: 384-397.

BROWN M.W., 2004 - Role of aphid predator guild in controlling Spiraea aphid populations on apple in West Virginia, USA. Biological Control, 29: 189-198.

Brown M.W., Mathews C.R., 2008 - Conservation biological control of spirea aphid, Aphis spiraecola (Hemiptera: Aphididae) on apple by providing natural alternative food resources. Eur. J. Entomol., 105: 537-540.

Brière J.-F., Pracros P., Le Roux A.Y., Pierre J.S., 1999 - A novel rate model of temperaturedependent development for arthropods. Environ. Entomol., 28: 22-29.

Cochran w.G., 1977 - Sampling Techniques. $3^{\text {rd }}$ ed., Wiley, New York, NY, USA.

CURRY G.L., FELDMAn R.M., 1987 - Mathematical Foundations of Population Dynamics. Texas Engineering Experiment Station (TEES). The Texas A\&M University System, Texas A\&M University Press, College Station, TX, USA, 246 p.

Di cola G., Gilioli G., BAUMgÄRTner J., 1999 - Mathematical models for age-structured population dynamics. - Ecological Entomology. HufFaKer C.B., Gutierrez A.P. (eds.), 2nd edition, Wiley, New York, pp.503-534.

FRAENKEL G.S., 1959 - The raison d'être of secondary plant substances. These odd chemicals arose as a means of protecting plants from insects and now guide insects to food. Science, 129: $1466-1470$.

Gutierrez A.P., 1996 - Applied Population Ecology. A Supply-Demand Approach. Wiley, New York, NY, $300 \mathrm{p}$.

GutierreZ A.P., BAUMgÄRTNer J., 2007 - Modeling the dynamics of tritrophic population interactions. - Perspectives in Ecological Theory and Integrated Pest Management. Kogan M., Jepson P. (eds.), Cambridge University Press, Cambridge, UK, pp. 301-360.

Hermoso de Mendoza A., Arouni R., Belliore B., Carbonell E.A., Pérez-Panadés J., 2006 Intervention thresholds for Aphis spiraecola (Hemiptera: Aphididae) on Citrus clementina. J. Econ. Entomol., 99(4): 1273-1279.

HoLST, N., RUGGLE P., 1997 - A physiologically based model of pest-natural enemy interactions. Exp. Appl. Acarol., 21: 325-341. 
Hong J., HAN K.S., Boo K.S., 2003 - Sex pheromone of Aphis spiraecola (Homoptera: Aphididae): composition and circadian rhythm in release. J. Asia Pacific Entomol., 6: 159-165.

Hoy M.A., Ru N., 2008 - Brown Citrus Aphid Parasitoid, Lipolexis scutellaris Mackauer (Insecta: Hymenoptera: Aphidiidae). Document EENY-181 (IN338) of the Featured Creatures series of the Entomology and Nematology Department, Cooperative Extension Service, Institute of Food and Agricultural Sciences, University of Florida. Published: November 2000. Reviewed: March 2008. Available online [http://edis.ifas.ufl.edu/pdffiles/IN/IN33800.pdf] [retrieved on May 19, 2010].

Hutchison W.D., Hogg D.B., Poswal M.A., Berberet M.C., Cuperus G.W., 1988 - Implications of the stochastic nature of Kuno's and Green's fixed-precision stop lines: sampling plans for the pea aphid (Homoptera, Aphididae) in alfalfa as an example. J. Econ. Entomol., 81: 749-758.

KARANDINOS M.G., 1976 - Optimum sample size and comments on some published formula. Bull. Entomol. Soc. Amer., 22: 417-421.

LimONTA L., Morlacchi P., BaUmgärTnER J., 2009a - Modello stocastico-biofisico per lo sviluppo di una coorte di Oulema duftschmidi a temperature costanti - Modelli per la difesa delle piante. Monografie e articoli scientifici presentate alle quarte giornate di studio su metodi numerici, statistici e informatici nella difesa delle colture agrarie e forestali: ricerca ed applicazione. Severini M., Pesolillo, S. (eds.), Viterbo, marzo 2007. Aracne, Roma: 177-181.

Limonta L., Locatelli D., Broglia T., Baumgärtner J., 2009b - Cohort developmental models for integrated Corcya cephalonica (Stainton) population management. Boll. Zool. Agr. Bachic., 41: 215-226.

Madeo M., Mingozzi M., Morlacchi P., Giorgi A., Onelli E., Lozzia G.C., Baumgärtner J., 2009 - Aphid infestations influence growth and bioactive compounds, and induce resistance in Achillea collina Becker ex Rchb. - Oral presentation at: Plants from High Altitude, Phytochemistry and Bioactivity. A joint Symposium of the Phytochemical Society of Europe (PSE) and the Austrian Pharmaceutical Society (OPhG). 26-29 April 2009. University Centre Obergurgl, Tyrol, Austria.

MiLLER T.E.X., 2008 - Bottom-up, top-down, and within-trophic level pressures on a cactus-feeding insect. Ecol. Entomol., 33: 261-268.

Morlacchi P., Brunella M., Giorgi A., LozZia G.C., BAuMgäRtner J., 2010 - Yarrow (Achillea collina) yield formation, aphid population fluctuations and sampling plans (Macrosphoniella millefolli, Aphis spiraecola, Coloradoa achilleae) in commercial alpine fields. J. Entomol. (subm. 2010).

Rykiel E.J. jr., 1996 - Testing ecological models: the meaning of validation. Ecol. Model., 90: 229-244.

SEverinI M., 2009 - Base matematica del Modello a Ritardo Variabile (Time Invariant Delay) - Modelli per la difesa delle piante. Monografie e articoli scientifici presentate alle quarte giornate di studio su metodi numerici, statistici e informatici nella difesa delle colture agrarie e forestali: ricerca ed applicazione. SEverini M. Pesolillo S. (eds.), Viterbo, marzo 2007. Aracne, Rome, pp. 13-57.

TAYLOR L.R., 1961- Aggregation, variance and the mean. Nature. 189:731-735.

TSAI J.H., WANG J.-J., 2001 - Effects of host plants on biology and life table parameters of Aphis spiraecola (Homoptera: Aphididae). Environ. Entomol., 30: 44-50.

VAnsickle J., 1977 - Attrition in distributed delay models. IEEE Trans. Syst. Man Cybern., 7: 635-638.

WANG J.-J., TSAI J.H., 2000 - Effect of temperature on the biology of Aphis spiraecola (Homoptera: Aphididae). Ann. Entomol. Soc. Am., 93: 874-883. 
WINK M., 2003 - Evolution of secondary metabolites from an ecological and molecular phylogenetic perspective. Phytochemistry, 64: 3-19.

Zulfaidah Penata Gama, M.Si., Biology Department, MIPA Faculty, Brawijaya University, Jl. Veteran, Malang 65145, Indonesia.

Pablo Morlacchi, Giuseppe Carlo Lozzia, Johann Baumgärtner, Dipartimento di Protezione dei Sistemi Agroalimentare e Urbano e Valorizzazione delle Biodiversità (D.I.P.S.A.), Università degli Studi di Milano, Via Celoria 2, 20133 Milano, Italy.

AnNa Giorgi, Dipartimento di Produzione Vegetale (Di.Pro.Ve.), Università degli Studi di Milano, Via Celoria 2, 20133 Milano, Italy.

Accepted 27 August 2010 